\title{
Salvador Dali e Amélia Toledo - Muito além de nossas emoções e sensibilidades
}

Sandra Regina Clara Nepomoceno Pinto ${ }^{1}$

\begin{abstract}
Neste texto falaremos de dois artistas que muito acrescenta ao Universo da Arte com seus trabalhos. 0 valioso presente que o mundo recebeu e que devemos ter muitos seguidores $e$ admiradores aplaudindo sempre a cada dia e agradecendo à importância desses mestres da arte. Falaremos de Salvador Dali na Arte Moderna e de Amélia Toledo na Arte Contemporânea. Também será visto a criatividade do trabalho acadêmico prático, desenvolvido na disciplina de 'Análise de Técnicas e Materiais Expressivos I em 2007-1'.
\end{abstract}

0 artista surrealista Salvador Felipe Jacinto Dali, comumente conhecido por DALI, nasceu em Figueras, Catalunha, na Espanha, em 11 de maio de 1904. Desde jovem teve talento para o desenho. A partir de 1927 foi atraído pelo

1 Aluna do Curso de Arte Visuais da UDESC - Universidade do Estado de Santa Catarina; autora do trabalho de conclusão - relato de experiência, da disciplina: Arte Moderna e Contemporânea, sendo a ministrante responsável a professora Dranda. Jociele Lampert. 
surrealismo, sendo este movimento iniciado em Paris. Dali criava obras ditadas pelo inconsciente através de sonhos. Em 1929, Dali começou a fazer parte do grupo surrealista com auxílio de Gala Eluard, a mulher que seria não só sua amante e esposa, mas também a sua musa inspiradora. Suas melhores obras estão no período de 1929 a 1939, usando um método de interpretação crítico-paranóico, baseado nas teorias da psicanálise, associando elementos delirantes e oníricos numa linguagem realista, com freqüentes imagens duplas e objetos do cotidiano. Sempre muito criticado, porém muito espontâneo, gostava do excêntrico e tudo o que poderia ser diferente do mundo real, assim fluía suas idéias e ideais para expor ao grande público sua arte. Foram muitos trabalhos deixados por Salvador Dali, entre eles estão cerca de 1500 quadros/pinturas, litografias, desenhos para livros, cenários e trajes de teatro, esculturas e muitos outros projetos. Mesmo após sua morte datada em 23 de janeiro de 1989 em Figueras, Catalunha, Espanha, o mundo foi palco desta metamorfose que foi em vida sua própria vida.

Falar, expor, dirigir, gesticular, apropriar, identificar, sentir, cheirar, fazer, são muitas as facetas por detrás do grande artista que foi DALI, sendo uma embriaguez falar de suas obras, todas despertam a curiosidade e muitos significados. Também podemos dizer que elas nos despertam tão somente um sentimento, mas vários: perplexidade, raiva, angústia, desolação, impotência e até superioridade. 
O mundo de DALI, em seu subconsciente, ou em seus sonhos, seria ele o próprio em suas obras. O ser onipotente, o glorioso perante aos outros, mas sedento de força para sair de uma situação conflituosa de seu mais temeroso pensamento: seguir adiante primeiro na trilha divina com os mistérios que envolvem o dia final. Com certeza não deixaria GALA que era sua melhor performance, ficariam juntos para muito além deste mundo. A tormenta de seu ser demonstra também delicadeza, sensibilidade, vulnerabilidade, impotência perante o cotidiano tumultuado sem ao menos perceber a beleza diante de um grão de areia. Portanto, vale ressaltar a preciosa arte de pintar, com sua impressão mais do que precisa em seus tons de cores, a luz e sombra, bem como a perspectiva visível em sua obra. Todos os detalhes minuciosos do desenho. Perante a toda exposição feita aqui, DALI ficou para a história da humanidade e suas obras sempre serão estudadas por muitas gerações.

Já Amélia Toledo com sua fala simples e singela traz sutileza e simplicidade do quão é glorioso produzir arte, como também estar de bem com o mundo em todas as etapas e idades vivenciadas. Idealizar e concretizar projetos, que por vezes estariam engavetados, ser cúmplice da dinâmica proposta por nós, deixando-nos enaltecidos. Vejo Amélia Toledo como um ser iluminado perante aos muitos expectadores que se encantam com tamanha sensibilidade. 
Atribuo em seu trabalho à facilidade de usarmos todos os nossos sentidos, que por sua vez nos faz entender os significados mais profundos em cada trabalho realizado pela artista. 0 uso das cores faz com que nossa visão fique muito mais apurada, o tato foi percebido no toque entre uma e outra pedra, metal, plástico, conchas, juta, resina de poliéster, bolas e outros, por sua vez o olfato, que fez sentir o odor característico de diversos materias usados pela artista, à audição, que fica por conta de conchas de praia que são penduradas em forma de gambiarra datada no ano de 1976, podendo ser balançada por nós, trazendo uma linda sintonia para nossos ouvidos, por fim a gustação, que sem dúvida alguma possa ser degustado de alguma forma alguns de seus trabalhos, como exemplo a areia do mar.

Fica claro que a artista utiliza lixos da natureza e os transforma em arte com a mistura de materiais industrializados, onde nos mostra um novo olhar, sendo a dualidade de seu trabalho. Muito me identifico com seus trabalhos, os diversos estilos, movimentos e técnicas trazidas pela artista serve de inspiração para aqueles que apreciam a arte contemporânea. Com certeza muitos críticos discordariam do meu parecer, sabendo que Arte Contemporânea lembra um grande laboratório de experimentação e arte nada mais é do que toda a expressão trazida para o mundo de diversas formas, sendo que cada uma tem seu valor. 
Em 2002 a Bienal de São Paulo recebeu mais de 670 mil visitantes, tornando-se a mostra de Arte Contemporânea mais visitada. Já para as pessoas cúmplices da época do Renascimento, onde as minúcias eram trazidas para uma tela, escultura ou mesmo papel, foi um tempo de aprendizado, onde não tínhamos muitos recursos, ficando para a história da humanidade, porém não podemos excluir esse momento que se fez e faz significativo, por outro lado o homem procura novos valores e os atribui com as inovações da indústria.

Acredito que devemos estar sintonizados com nosso meio para não sermos pegos de surpresa. É típico em uma Bienal de Arte Contemporânea, um grupo de alunos conhecerem trabalhos e obras de muitos artistas consagrados: pinturas com guache de Hélio Oiticica, esculturas de Amílcar de Castro, pinturas de Picasso e Tarsila do Amaral e outros. No Universo da Arte você é levado para uma realidade verídica sem cortes e que dependendo de nossa sensibilidade muitos fatos deixarão de existir, pois o canal não está aberto para o novo. Claro que devemos aproveitar cada minuto de nossa vida, porém nem todo dia conseguimos captar determinadas informações e vislumbrar o belo ou o incompreendido.

$\mathrm{Na} 27^{\mathrm{a}}$ Bienal de Arte de São Paulo em 2006, o vídeo 'Birth of Love' apresentado pelo artista Adel Abdessemed, 1971 que vive em Paris, França, nos revela alguns significados da Arte Contemporânea em nossos dias. Afinal o 
vídeo estava em uma posição estratégica da Bienal e poderia ser visto por todos que passavam. O trabalho chamado 'Nascimento do Amor' emerge a Arte Contemporânea. A filmagem de um gato comendo um rato por vários minutos e sendo repetido durante todo o evento. A cena comum vivenciada pelo gato, trazido para dentro de uma Bienal causou estranhamento em muitas pessoas. É assim que ficamos perplexos e horrorizados com determinados trabalhos, pois acreditamos que já fizemos coisa de igual ou superior dimensão. Para isso acontecer devemos nos expor ao mundo, para nos tornar um artista completo, sendo que multidões de pessoas e críticos sedentos por matéria e notícias possam transgredir a nossa imagem ou quem sabe enaltecer. Mas se dermos toda a atenção devida e correta para aqueles que querem nos enforcar, parece que amenizamos suas expectativas e assim nos mostramos ao mundo como somos: perfeitos ou imperfeitos? É só uma questão de ângulo daqueles que nos vêem.

Amélia Toledo organiza o lixo da natureza transformando em peças luxuosas, mostra a beleza que por vezes estaria esquecida. A junção entre o metal e a pedra traz novas formas e significados ao mundo. As diversas obras da artista nos refletem com exatidão todo e qualquer contato realizado até o momento entre nós e o mundo. Nada é novo, pois já os conhecemos e desfrutamos, é só uma questão de disposição e enfrentamento que fizemos para nós e o mundo. Se passarmos nossos dias 
enfornados dentro de nossos casulos, jamais vamos ter a oportunidade de elevar nossos pensamentos e por em prática nossas idéias. Afinal somos todos, seres capazes e racionais. Por fim, nada é tão ruim que não possa ser melhorado, e assim apreciado e desejado por muitos.

Quanto ao processo criativo, foi muito significativa sua realização, pois ao materializar uma idéia, surgem diversas expectativas quanto à concretização. 0 trabalho foi guiado por Salvador Dali na Arte Moderna e de Amélia Toledo na Arte Contemporânea, fazendo a união de um trabalho único e individual, sendo um desafio para ambos: aluno e professor, mas o resultado foi o esperado sem obstáculos.

Amadurecer a idéia foi mais uma prova que estamos no caminho certo, sem buscar longe nossas metas para alcançar o objetivo principal que era criar todo um cenário para que um gato se sentisse atraído e compartilhasse do trabalho. Então surgiu o passo importante: gato gosta de peixe. Até o momento tudo bem, mas o surrealismo, onde está? Um aquário de vidro poderia dar a sensação que fosse a barriga do peixe. Um pouco de água e tinta vermelha poderia ficar mais real e ovos para que a cor vermelha fique com gordura e mais espessa. É certo falar que tudo foi meticuloso ao montar e soltar o gato para o trabalho se 'transformar', assim o título 'transformação'. Foram cem fotos no power point, apresentadas na disciplina de Análise de Técnicas e Materias Expressivos I. 
Segue algumas fotos importantes do trabalho realizado.

\section{Cenário}

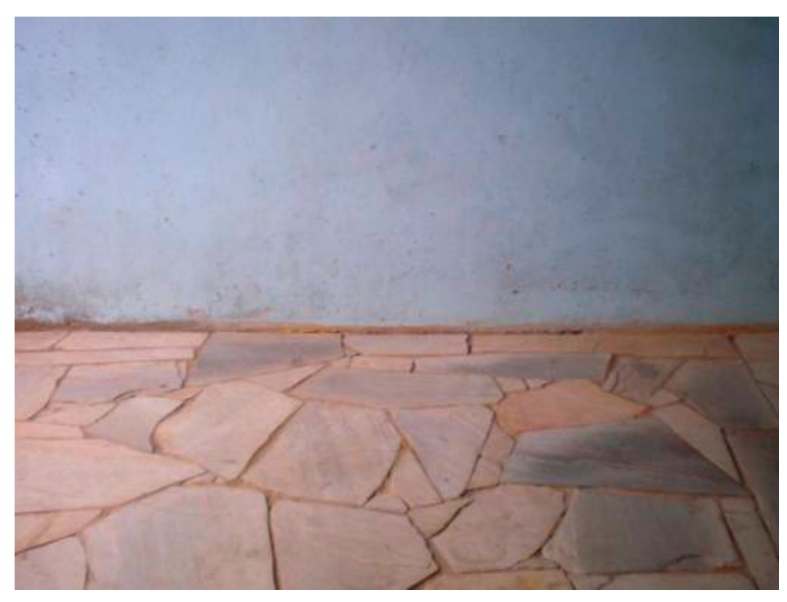

Material usado durante o processo criativo

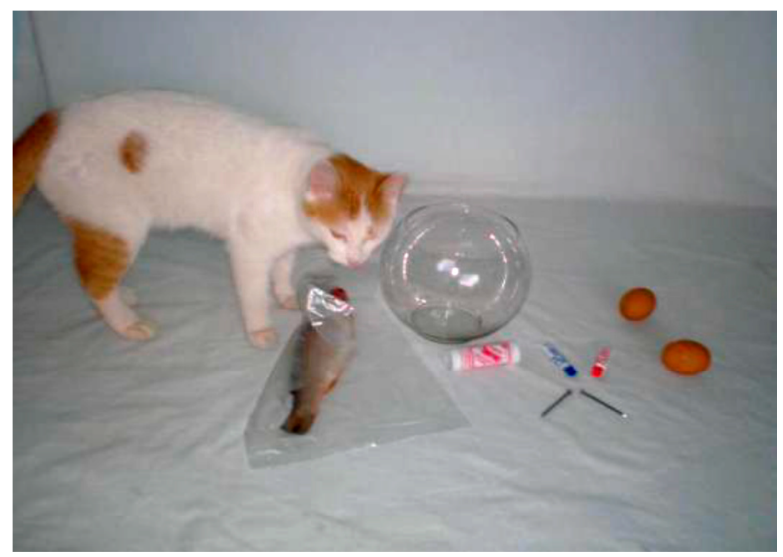



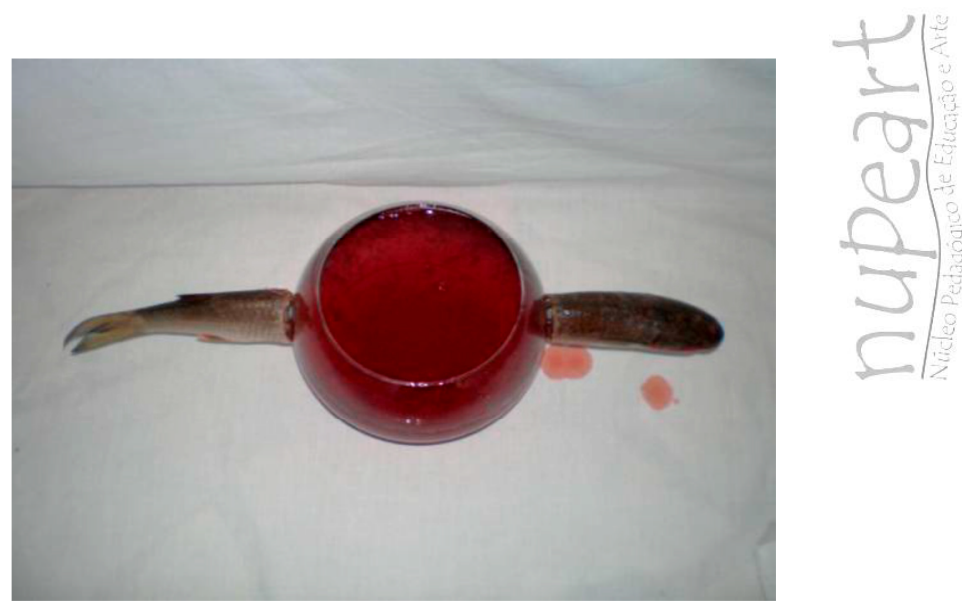

Processo em transformação com a ação do gato

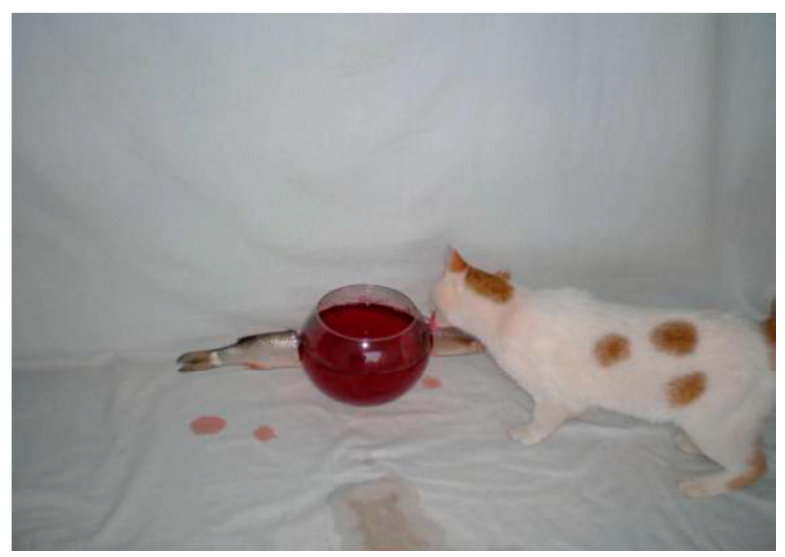



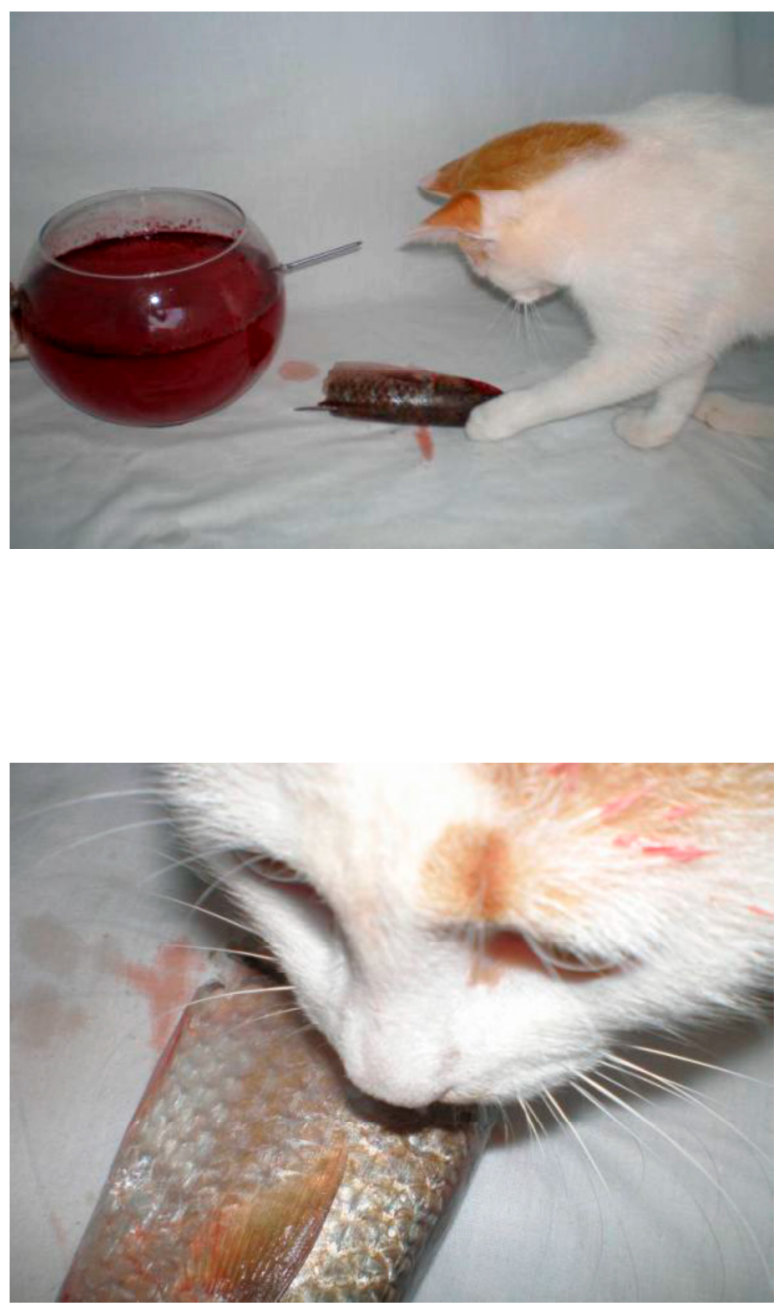
Doze horas após e...
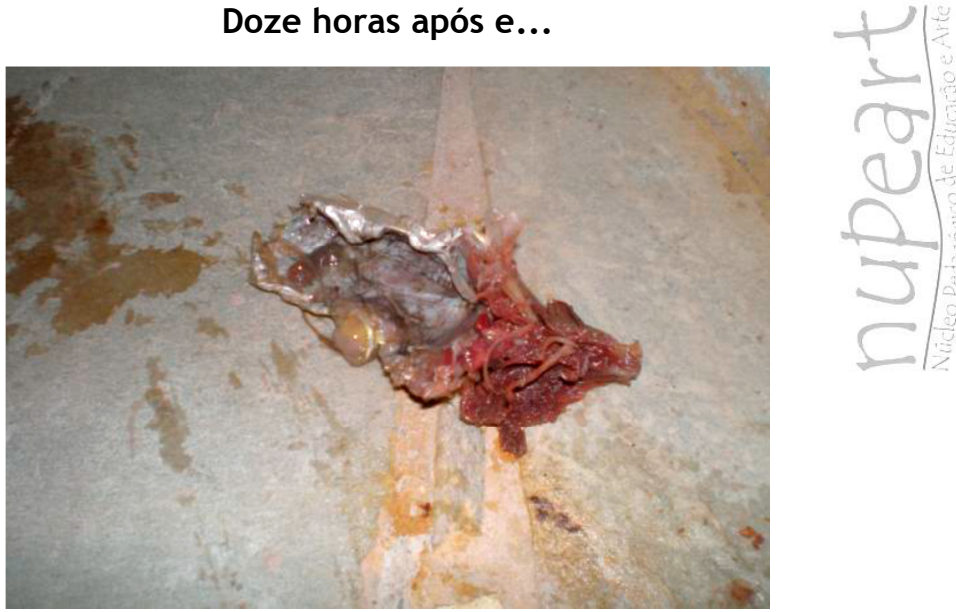

\section{Cenário desconfigurado}

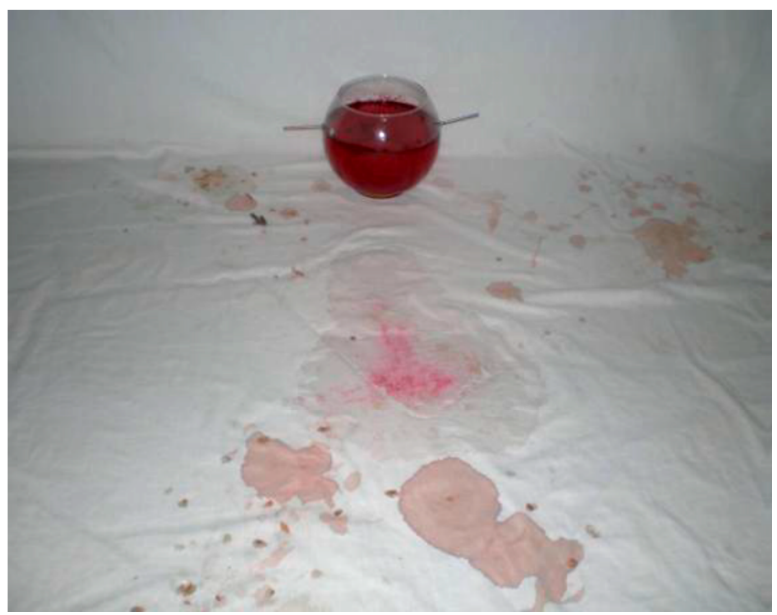


Após vinte e quatro horas...

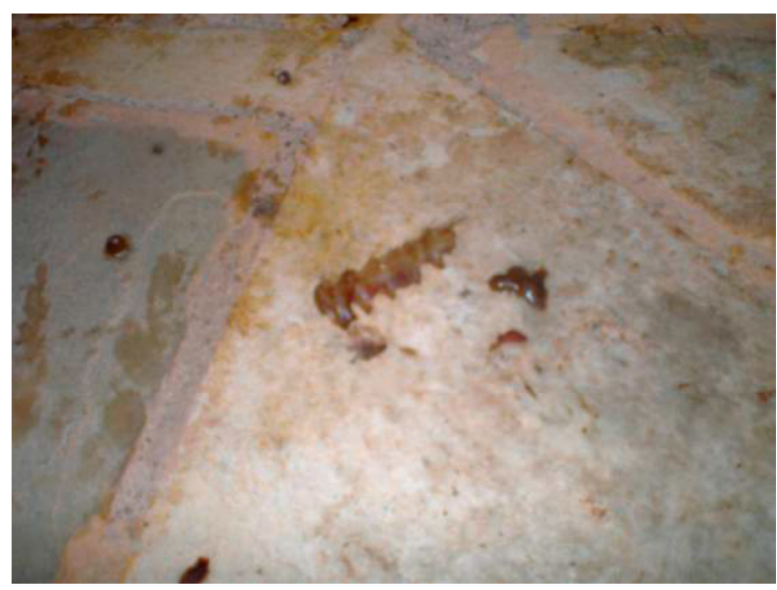

Aqui voltamos ao começo de tudo, para que muitas outras idéias possam surgir.

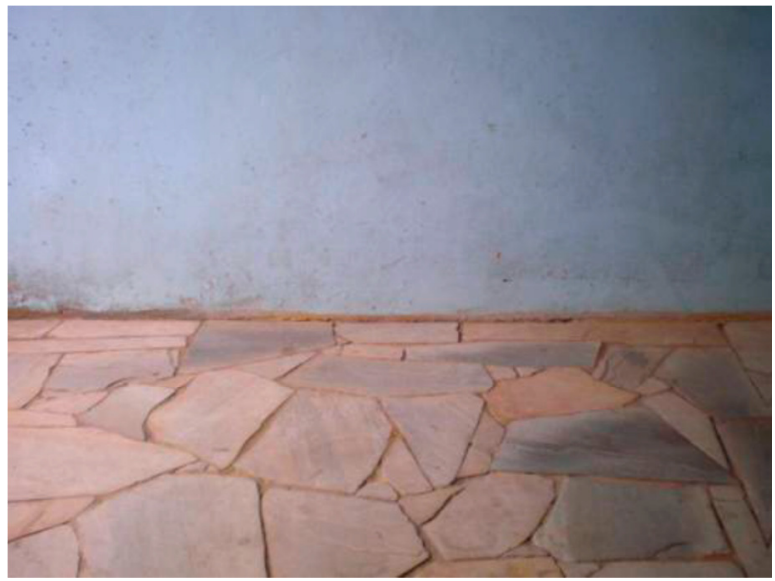


0 momento na qual deixamos fluir nossos pensamentos e os concretizamos é válido e será sempre bem vindo de forma real e preciosa no mundo das artes. E cada dia aprende-se mais sobre a imensidão de teorias que surgem a cada dia. A arte propriamente dita e toda a nossa sensibilidade que colocada durante o processo de criação sempre será vista de forma mágica e compensatória, pois, ninguém neste mundo poderá nos retirá-la após a concretização de um projeto. 0 ato de criar nos eleva a alma e traz para este mundo o belo para ser apreciado, assim estamos dando continuidade à história da arte para as gerações que estão por vir.

Portanto, com esse trabalho me fez acreditar na importância da Arte Moderna e Contemporânea para nossos dias. Acredito que esta cena poderia passar despercebida e comum por muitas pessoas, mas vista em um trabalho ela causa um estranhamento, certa inutilidade, mas sem dúvida relevante para nosso ensinoaprendizagem. 


\section{Referências bibliográficas}

FARIAS, Agnaldo. Amélia Toledo: as naturezas do artifício. São Paulo, Editora W11 editores, 2004.

JACQUELINE, Chénieux-Gendron. O Surrealismo. São Paulo. Ed Martins Fontes, 228p. 1992.

Http://pt.whkipedia.org/wiki/salvador_dali. Acesso dia 10 de jun. de 2007 http://www.rainhadapaz.g12.br/projetos/artes /dali/biografia.htm Acesso dia 13 de jun. de 2007

http://www.pitoresco.com.br/universal/dali/da li.htm Acesso dia 20 de jun. de 2007

http://www.acrilex.com.br/AC/historia/index_ contempo.php Acesso dia 20 de jun. de 2007.

http: / / kplus.cosmo.com.br/materia.asp?co=147 \&rv=Literatura Acesso dia 20 de jun. de 2007

http: / /www.nettime.org/ListsArchives/nettime-lat-0210/msg00021.html Acesso dia 20 de jun. de 2007 http://www1.uol.com.br/ameliatoledo/home.h tm Acesso dia 20 de jun. de 2007

http: / / universes-in-universe.de/car/saopaulo/esp/2006/tour/img-11.htm Acesso dia 22 de set. de 2007. 